\title{
Rainfall and temperature variation does not explain arid species diversity in outback Australia
}

This article was published in the following Dove Press journal:

Research and Reports in Biodiversity Studies

5 July 2013

Number of times this article has been viewed

\section{Lochran W Traill' \\ Thomas C Wanger ${ }^{2,3,4}$ \\ Siobhan C de Little' \\ Barry W Brook'}

'Environment Institute and School of Earth and Environmental Sciences,

University of Adelaide, Adelaide, SA,

Australia; ${ }^{2}$ Center for Conservation

Biology, Department of Biology,

Stanford University, CA, USA;

${ }^{3}$ Ecosystem Functions, Leuphana

University Lüneburg, Lüneburg,

Germany; ${ }^{4}$ Agroecology, Department

of Crop Sciences, University of

Göttingen, Göttingen, Germany
Correspondence: LW Traill Imperial College London, Silwood Park, Berkshire SL5 7PY, UK

Tel +442075942470

Email lochran.traill@gmail.com
Abstract: Steps toward conserving biodiversity should start at understanding the components across spatial scales and a determination of the drivers of these. Here we determine additive species diversity for arid South Australia, based on over 50 years of survey data. Elevation and soil data were sourced through the Australian Government, and climate data from the WorldClim database. Alternative hypotheses relating the effect of climatic and environmental parameters to diversity were tested using generalized linear models and ranked according to information-theoretic statistics. Total species richness for the region was 1824, similar to all arid regions. $\alpha$-diversity values were low, relative to the contributions made by $\beta$-diversity toward total $\gamma$-diversity, similar to additive diversity indices for nonarid biomes. There was a lack of statistical support for our hypothesis that regional spatial variation in arid region diversity can be explained by climate topography. Arid South Australian species diversity appears to be largely driven by environmental parameters at the localized scale - beyond the resolution of available survey data. Heterogeneity in habitat, provided by mountainous regions, likely contributes toward the high $\beta$-diversity values. Our research is the first application of the additive (not multiplicative) approach toward understanding diversity within arid Australia.

Keywords: additive diversity, arid biome, South Australia, generalized linear models, global climate models, species richness

\section{Introduction}

The maintenance of biodiversity is central to the practice of conservation biology. ${ }^{1}$ Biodiversity confers system resilience to change and disturbance ${ }^{2}$ - given that different species respond in different ways to environmental pressures - thereby providing a more robust aggregate community. ${ }^{3,4}$ Such ecosystem resilience is pertinent to present-day conservation management as human populations continue to grow $^{5}$ and exert impacts (eg, habitat alteration, introduction of invasive species) that may act in synergy with climatic shifts to alter community composition and structure. ${ }^{6,7}$ In this context, biodiversity-related research will likely move from a focus on understanding spatial-temporal changes in diversity toward improved explanation of the underlying mechanisms of change and the capacity of ecological communities to adapt.

The term "biodiversity" is synonymous with species diversity, or the temporal and spatial heterogeneity of communities, ${ }^{8}$ and has been in common usage since the Rio 1992 International Convention on Biological Diversity. Numerous biotic and abiotic factors can determine such heterogeneity, including rainfall, topography, temperature, aspect, evolutionary history, and anthropogenic activity. ${ }^{1,9,10}$ Naturally, species diversity will vary across broad biomes, as a consequence of both localized submit your manuscript $\mid$ www.dovepress.com

Dovepress

http://dx.doi.org//0.2147/RRBS.S4030।
Research and Reports in Biodiversity Studies 2013:3 I-8

(C) 2013 Traill et al, publisher and licensee Dove Medical Press Ltd. This is an Open Access article which permits unrestricted noncommercial use, provided the original work is properly cited. 
and environmental effects, ${ }^{1,11}$ but as a generalization, data indicate a relationship between diversity and productivity, such as soil or climate effects, ${ }^{3}$ with an asymptotic increase in richness with increased rainfall. ${ }^{12}$ This most basic definition of diversity is based on the number of species within a region, but another estimate of diversity is the difference in the number of species between regions, with quite different implications. To elaborate, the most common measure of diversity is species richness, or simply the number of genetically distinct species that occupy a predefined region. ${ }^{13}$ $\alpha$-diversity accounts for species' relative abundance within a plot or community, and is thereby a measure of average diversity. The magnitude of species turnover or spatial variation between communities is quantified through $\beta$-diversity, ${ }^{13}$ and together these contribute toward total, or $\gamma$-diversity, within a region.

The factors that drive $\alpha$-diversity within a region may be different from those factors that drive $\beta$-diversity. For example, within central arid Australia, $\beta$-diversity tends to be high relative to the more tropical north, but $\alpha$-diversity is lower. ${ }^{14}$ Localized factors such as habitat heterogeneity or human activity can lead to relatively high levels of $\beta$-diversity within a region, ${ }^{14,15}$ but mean $\alpha$-diversity tends to be associated with mean annual rainfall. ${ }^{14}$ It is for these reasons that $\gamma$-diversity can be useful in determining "total" diversity for a particular region, or as a comparative index of change through time.

Most commonly, a multiplicative approach is used to determine $\gamma$-diversity; thus, $\gamma=\alpha \times \beta$, as per Whittaker. ${ }^{16}$ The practical disadvantage of this approach is that the diversity components are not weighted equally when partitioned across more than one spatial scale. ${ }^{17}$ As an alternative to the multiplicative approach, measures of diversity can be partitioned additively: eg, Veech et al. ${ }^{18}$ Thus, the observed $\gamma$-diversity $\left(\gamma_{\text {obs }}\right)$ can be partitioned as $\gamma_{\text {obs }}=\alpha+\beta_{\mathrm{S}}+\beta_{\mathrm{R}}$, where $\beta_{\mathrm{S}}$ is the between-site $\beta$-diversity, and $\beta_{\mathrm{R}}$ is the between-region $\beta$-diversity. ${ }^{19}$ This provides for estimation of the relative contributions of $\alpha$ - and $\beta$-diversity, thereby allowing for comparative spatial studies that are more pertinent to conservation decision making. ${ }^{19}$ Further, the additive approach is more straightforward than the multiplicative approach, and as the diversity components are expressed in the same units, the additive approach allows for partitioning on an unlimited number of scales. ${ }^{19}$

To date, analyses that have used an additive partition approach for species diversity have been applied within temperate, ${ }^{20}$ tropical, and subtropical regions, ${ }^{21,22}$ as well as marine systems. ${ }^{23}$ However, there is an apparent lack of additive diversity research within arid and semiarid regions (a search using the ISI Web of Science [http://www. isiknowledge.com] showed just five peer-reviewed articles since 1973). In fact, relatively little diversity-related research has been conducted in arid and semiarid regions at all, despite many threats to arid species persistence being identified. ${ }^{24,25}$ What is more, the world's arid regions cover up to $41 \%$ of the global ground surface, and support up to $38 \%$ of the global human population. ${ }^{26}$

Moreover, although it is accepted that climate and topography influence species diversity, ${ }^{9}$ and that projected shifts in climatic parameters will shape future distributions in diversity, ${ }^{27}$ we know of few studies that have used additive diversity indices to test for correlative climatic effects, and no studies for arid regions. Bowman ${ }^{14}$ and, more recently, James and Shine ${ }^{9}$ did explore the influence of climate on arid species diversity, but these were based on the multiplicative approach.

Here we apply the additive diversity approach to an extensive arid region likely to experience shifts in temperature and rainfall regimes in the coming decades - namely, outback South Australia (SA). We determine diversity indices based on SA survey data, develop a competing hypothesis framework to tease apart the regional drivers of diversity, including climatic factors, and discuss the conservation implications for arid region diversity under global change.

\section{Material and methods Data acquisition and processing}

Data were restricted to the Alinytjara Wilurara Natural Resource Management (AWNRM) region, SA (Figure 1). This extensive $\left(\sim 250,000 \mathrm{~km}^{2}\right)$ yet sparsely populated region is set aside for conservation and indigenous land use (see http://www.awnrm.sa.gov.au).

The study area falls within the arid climatic zone, ${ }^{9}$ or the desert and xeric shrubland ecoregion. Temperatures for our (entire) study region ranged from $3.6^{\circ} \mathrm{C}$ to $35.4^{\circ} \mathrm{C}$ (mean $20.8^{\circ} \mathrm{C}$ ), and mean annual rainfall was $18 \mathrm{~mm} .{ }^{28}$

Major vegetation communities, as classified by the National Vegetation Information System (NVIS), ${ }^{29}$ include Acacia woodlands, Mallee woodlands and shrublands, Eucalypt woodlands, and hummock grasslands. Human communities are widely dispersed, with an estimated total population of $\sim 4000$ people (http://www.awnrm.sa.gov.au).

All species data were sourced by permission of the South Australian Department of Environment, Water and Natural Resources (http://www.environment.sa.gov.au). These were part of a state-wide, ongoing survey of threatened and 


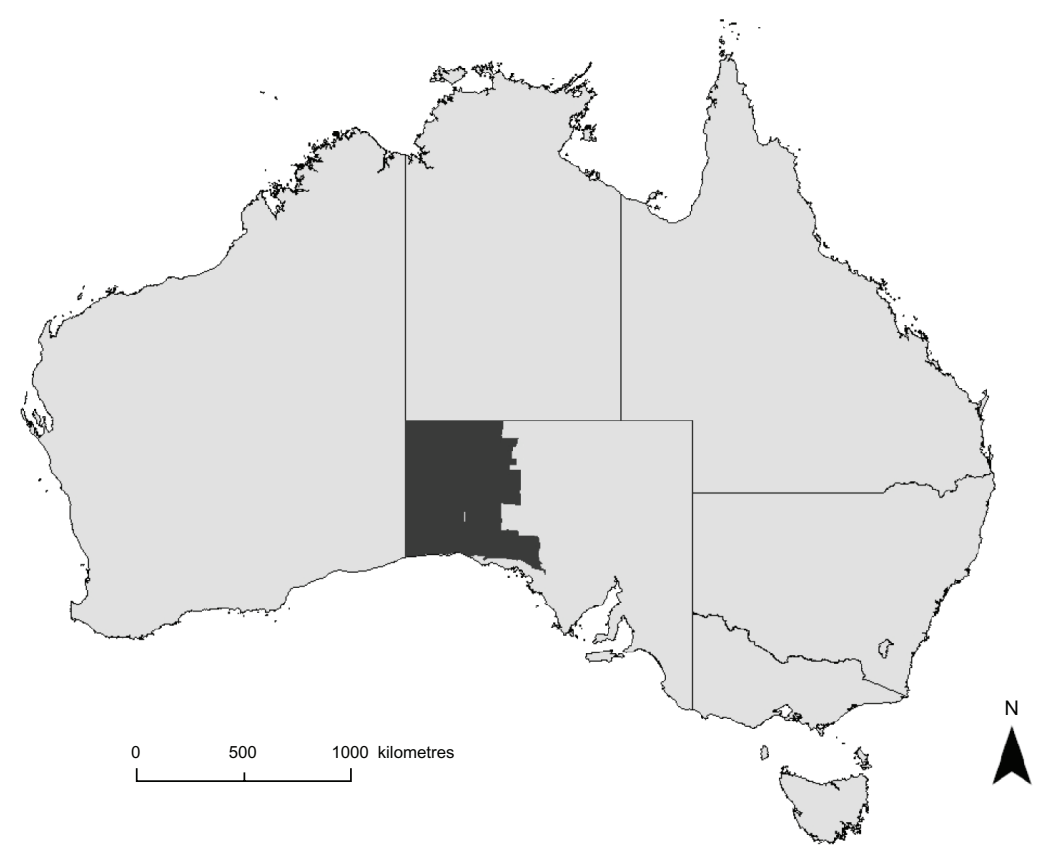

Figure I Outline of the Alinytjara Wilurara Natural Resource Management region (black) of South Australia, with the continent of Australia outlined in grey and lines demarcating each state and territory.

nonthreatened species (plants and vertebrates only). Each year, the South Australian Department of Environment, Water and Natural Resources conducts transect- and quadrat-based biological surveys to catalogue information on plant and terrestrial vertebrate species distribution.

Data were first segregated into general taxonomy (class for vertebrates [amphibians, birds, mammals, and reptiles] and then plants), and duplicate or erroneous data were omitted. Abundance data were not available for most survey counts, so only presence data were used. Species location data allowed spatial representation within the Geographic Information System (GIS) software ArcGIS (ArcMap software, v.9.3, ESRI, Redlands, CA, USA).

Before we could derive diversity indices we needed to delineate ecological boundaries. Biological survey data were not collected in a stratified random manner; rather, they were widely distributed (apparently following roads). To account for the broad spatial scale of these data and uneven spatial sampling, we chose major vegetation groups (MVGs) as the ecological communities to analyze, following the NVIS. ${ }^{29}$ GIS spatial data (shapefiles) for these groups were sourced from the NVIS web link (http://www.environment.gov.au/ erin/nvis) and processed using ArcGIS software.

\section{Diversity assessment}

Species data were first resampled (bootstrapped random samples, with replacement, within each MVG) to mitigate against the confounding effects of spatial autocorrelation. ${ }^{30}$ Diversity measures were then calculated following the formulae provided by Clough et $\mathrm{al}^{19}$ - first $\alpha$-diversity, then $\beta_{\mathrm{S}}$ (between-sites, within MVGs) and $\beta_{\mathrm{R}}$ (between region, or MVG), and from these $\gamma$-diversity. Coding for these was implemented in the $\mathrm{R} v 2.12$ language (http://www.r-project. org) and is available from the authors on request.

\section{Climate and environmental data}

Given the global climate model-based forecasts of climate change in the region over the next few decades, including a general warming and drying trend, ${ }^{31}$ we were interested in the effects of temperature and rainfall on arid region diversity. Thus, we sourced climate data (as GIS raster files) through the WorldClim project, ${ }^{28}$ and collated mean annual temperature and mean annual rainfall for the region. In order to calculate the mean values for each MVG, we used the extract function in ArcMap to allocate temperature and rainfall values to each datapoint (species location data), and averaged these across MVGs.

WorldClim's current climate data account for variance in rainfall and temperature over the last 50 years, so we excluded all species location data that predated 1960 . Thus, diversity indices were derived from pooled survey data, ranging over the past five decades.

In addition to the influence of climate on additive diversity, we sourced data for those environmental parameters likely 
to determine diversity. These were rainfall (mean annual), temperature (mean annual), elevation, geology or dominant soil type, fire history, and disturbance (in particular, the presence of large ungulates and other ferals).

We did not have spatial data available for fire history, given the vastness of the area and the lack of records for Aboriginal burning programmes (practiced in an informal, traditional manner). Further, we considered the impact of feral vertebrates to be homogenous, given that their ubiquitous distribution ${ }^{32}$ and abundance data were not available for cattle (Bos taurus).

Past research has indicated the importance of elevation and soil type in driving diversity patterns. ${ }^{14,33}$ Therefore, we sourced the Advanced Spaceborne Thermal Emission and Reflection Radiometer Global Digital Elevation Model, with a posting interval of 1 arc-second (http://asterweb.jpl.nasa. gov/data.asp). Elevation data were processed in ArcGIS, and we clipped an area appropriate to our study area. We then used species presence data to extract elevation at occupied points in the landscape, and averaged these across each community to derive mean elevation by MVG.

Soil data were extracted as a GIS shapefile from the Australian Natural Resources Data Library (http://www. daff.gov.au/abares/data), based on the Northcote ${ }^{34}$ principal profile classification scheme. We required a soil value across each vegetation group, and so determined dominant soil type (majority of spatial distribution) for each community and allocated data (to MVGs) accordingly.

\section{Correlative models}

We used generalized linear models ( $\gamma$-distribution with log link) using maximum likelihood estimation to fit the models, and information-theoretic, multi-model inference metrics ${ }^{35}$ were then used to identify the suite of climate and environmental parameters that best explained variation in additive species diversity. Analyses were implemented within the R language, and model weights were assessed using Akaike's Information Criterion, adjusted for finite sample size ( $\left.\mathrm{AIC}_{c}\right)$.

Of note, we were limited to fitting one- or two-term models only, because initial analyses showed our saturated model to be overparameterized (too few data points per estimated parameter, given that we used averaged values for each MVG and therefore had a limited number of independent data points available). Thus, our competing models (hypotheses) consisted of single-term models for each predictor, and the possible additive combinations between climatic and environmental parameters.

\section{Results}

Summed species occurrence across NVIS communities showed high values within Mallee woodlands and shrublands, Acacia open woodlands, and Acacia and Chenopod shrublands (Table 1). Proportionally, the NVIS groups Acacia shrublands and Mallee woodlands and shrublands represent the greater part of land within the AWNRM region, at $\sim 46 \%$ of land cover. Acacia open woodlands represent just $\sim 9 \%$ of total land cover, however, despite having relatively high species representation (Table 1). The summed total of unique species across the entire region was 1824 . Note that this value is different from the summed total for values in Table 1 ( 7989), as many species occur across multiple communities.

$\alpha$-diversity was relatively low in Acacia forests and woodlands and high for Acacia open woodlands, Acacia shrublands, Chenopod shrublands, and Samphire shrublands and forblands (Table 1). Summed $\beta$-diversity values were

Table I Major vegetation groups (MVGs) and species richness for the Alinytjara Wilurara Natural Resource Management region, South Australia, based on the National Vegetation Information System (NVIS; DEWR 2007)

\begin{tabular}{lllll}
\hline Vegetation type, based on the NVIS & MVG code & Area $\mathbf{~ k m}^{2}$ & Total species & $\alpha$-diversity \\
\hline Acacia forests and woodlands & 6 & 5575 & 444 & 2.97 \\
Acacia open woodlands & 13 & 26225 & 928 & 10.66 \\
Acacia shrublands & 16 & 62300 & 838 & 10.39 \\
Casuarina forests and woodlands & 8 & 7050 & 473 & 9.26 \\
Chenopod shrub, samphire shrub, and forblands & 22 & 44300 & 839 & 10.79 \\
Eucalypt open woodlands & 11 & 32125 & 726 & 9.82 \\
Hummock grasslands & 20 & 7275 & 757 & 9.67 \\
Inland aquatic & 24 & 50 & 85 & 6.31 \\
Mallee woodlands and shrublands & 14 & 69175 & 1279 & 9.62 \\
Other shrublands & 17 & 10300 & 719 & 6.88 \\
Tussock grasslands & 19 & 23100 & 772 & 6.98 \\
\hline
\end{tabular}

Note: Data include NVIS coding (see http://www.environment.gov.au/erin/nvis), spatial area $\left(\mathrm{km}^{2}\right)$, sum of species within each respective community (Alinytjara Wilurara Natural Resource Management region only), and $\alpha$-diversity values derived at the community scale. 
substantially higher than $\alpha$-diversity (Figures 2 and 3), and contributed greatly to $\gamma$-diversity (mean of $97 \%$ across all MVGs). Percentage $\alpha$-diversity contribution toward $\gamma$-diversity was low across most of the major NVIS communities (Figure 3), except for Casuarina forests and woodlands (NVIS MVG8) and inland aquatic (MVG24).

Models testing statistically for the influence of climate, elevation, and soil on arid-zone diversity were not supported by the data, with the null expectation (ie, the same average diversity across all MVG types) being selected for all three diversity compartments (Table 2). This may be partly a problem with statistical power, because we had so few data points (climate data were averaged across MVGs, leaving eleven independent points, or 3.5 data points per parameter). Mean annual rainfall did capture some of the variance ( $\%$ deviance explained [DE]), however, for all diversity indices (Table 2), as did elevation, showing that the structural goodness of fit of the model was adequate.

Mean annual rainfall and mean elevation by MVG were strongly correlated $(R=0.903)$. Of note, Fawcett et $\mathrm{al}^{36}$ showed that there was an increase in annual rainfall (over the last century) in the northern part of SA, where elevation is higher (by as much as $550 \mathrm{~m}$ ), and this was captured by the WorldClim rainfall data.

Further, we derived evidence ratios (ER; as a measure of comparative support) for the mean annual rainfall and mean annual temperature models. These were calculated by summing the weighted $\mathrm{AIC}_{\mathrm{c}}$ values (Table 2) and dividing the sum of these for all rain and temperature models (thus, the ratio for

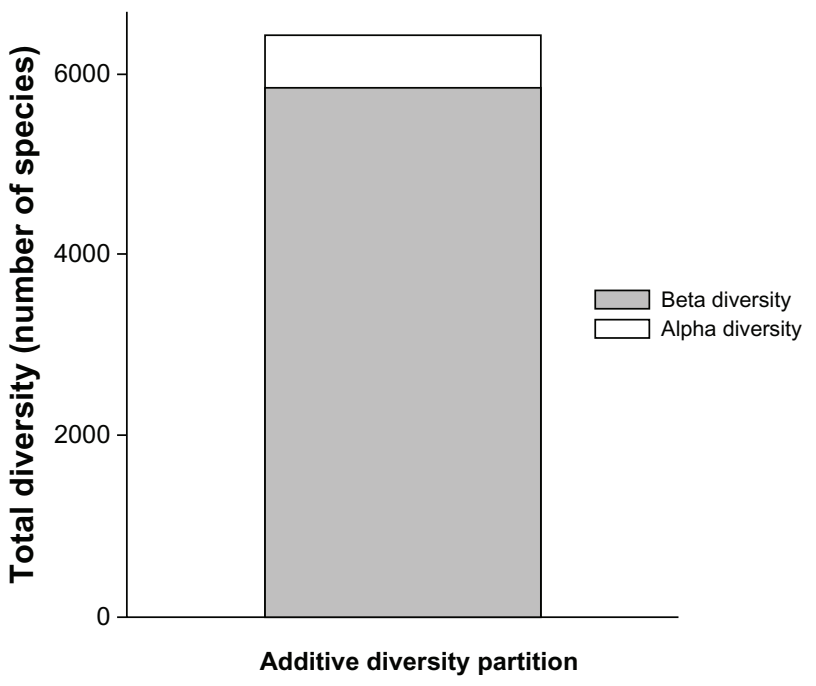

Figure 2 Additive species diversity for the entire Alinytjara Wilurara Natural Resource Management region (all vegetation groups), showing both $\alpha$ - and $\beta$-diversity $\left(\beta_{\mathrm{s}}+\beta_{\mathrm{R}}\right)$ and respective contribution toward $\gamma$-diversity, where $\alpha$ is the mean $\alpha$-diversity per site, $\beta_{s}$ is the between-site $\beta$-diversity and $\beta_{R}$ the mean between-region $\beta$-diversity, and the respective contribution of these to total regional diversity, or $\gamma$-diversity. evidence between models that contained these parameters). Rainfall models showed twice as much support from the data for all three diversity components (rainfall versus temperature $\mathrm{ER}, \alpha$-diversity $=2.2 ; \beta$-diversity $=2.2 ; \gamma$-diversity $=2.3$ ).

\section{Discussion}

The total species richness for plants and vertebrates across arid and semiarid SA, at 1824 species, is similar to analogous arid regions. For example, Stohlgren et $\mathrm{al}^{33}$ estimated total species occurrence (plants only) at $\sim 700$ in Utah, US, and Waide et $\mathrm{al}^{37}$ list total species richness, again in the arid US, at 535 and 814 (excluding plants), and 1341 and 2261 (including plants). Total species count for plants in arid SA was 1387, and total vertebrates was 437 .

Of interest, and to provide a global context, the International Union for Conservation of Nature and Natural Resources (http://www.iucnredlist.org) lists the total number of described vertebrate species as 63,161 and total described plants as 307,674 . The greater part of these species occur in the tropics, with a general biogeographic trend showing a peak in the tropics, apparently correlated with annual rainfall. ${ }^{38}$ Thus, Bowman ${ }^{14}$ recorded relatively high $\alpha$-diversity in tropical northern Australia and a decline along the southwards latitudinal gradient toward arid central Australia (but a noted increase in $\beta$-diversity). Further, anuran diversity has been found to be relatively low in arid Australia compared with other regions across the continent, ${ }^{39}$ and songbird species are notably scarce in the outback, compared with more tropical parts of the country. ${ }^{40}$ The latitudinal generalization does not hold for all taxa, however. For example, James and Shine ${ }^{9}$ found that $\alpha$-diversity values for Australian Ctenotus skinks peaked in the arid center, suggesting that the relative homogeneity of arid climatic conditions allowed for greater sympatric speciation. ${ }^{9,41}$

Our data exclude tropical northern Australia, but we do note that our diversity indices were correlated with annual rainfall (up to $16 \%$ of DE, Table 2 ) and elevation (9\% of $\mathrm{DE}$ ), with a trend of increased $\beta_{\mathrm{s}}$-diversity following the latitudinal gradient from south to north (elevation in arid outback Australia increases toward the center). Although we recognize the correlation between rainfall and elevation in our data, ongoing research has indicated the importance of elevation in driving species diversity, particularly $\beta$-diversity. For example, Bowman ${ }^{14}$ noted a strong correlation with $\beta$-diversity and elevation, as did Simmons and Cowling ${ }^{42}$ in South Africa. These authors suggest that the heterogeneity in habitat provided by areas of greater elevation, such as the increased influence of aspect (due to rocky or broken terrain) 


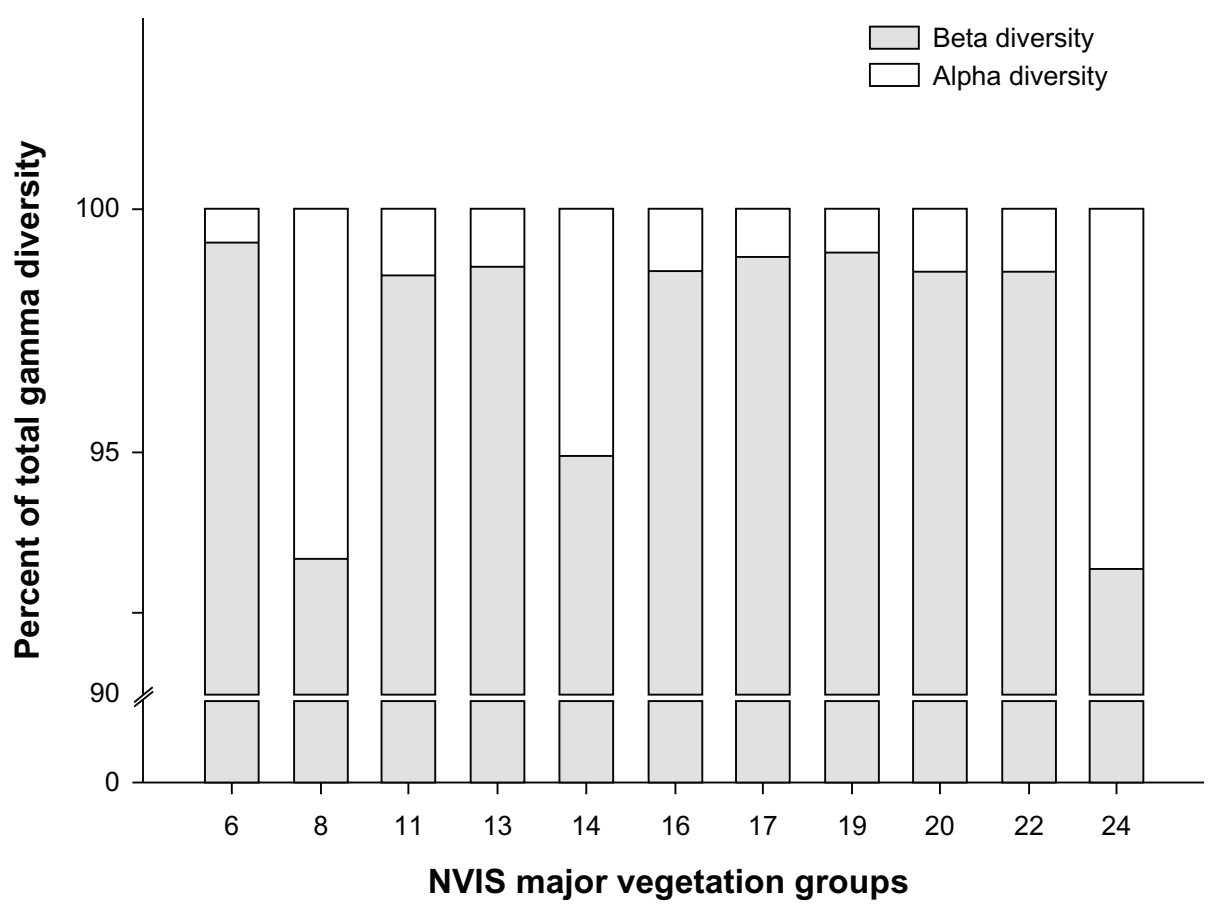

Figure 3 Additive site diversity across vegetation communities in the Alinytjara Wilurara Natural Resource Management region, South Australia. Shown are the percentage contributions made by $\alpha$ - and $\beta$-diversity toward $\gamma$-diversity. Note the break from $10 \%$ to $80 \%$ on the $Y$-axis, done to provide a clearer illustration of additive differences between communities: where $\alpha$ is the mean $\alpha$-diversity per site, $\beta_{\mathrm{s}}$ is the between-site $\beta$-diversity and $\beta_{\mathrm{R}}$ the mean between-region $\beta$-diversity, and the respective contribution of these to total regional diversity, or $\gamma$-diversity.

Abbreviation: NVIS, National Vegetation Information System.

and altitude, provide for resource partitioning and thus greater diversity of species between sites.

Such findings are particularly relevant to biodiversity conservation under shifting climates. For example, recent research in the Swiss $\mathrm{Alps}^{43}$ has shown that variation in micro-habitat temperature (driven by micro-topography and aspect) allows for greater diversity in (plant) species richness, and that a warmer world will affect only the species confined to the coldest micro-habitats, with the majority of plants finding suitable micro-habitats within just a few meters. We speculate that topographic variability in arid central Australia might provide biodiversity refuge to climate change, relative to more low-lying, flat arid areas. ${ }^{43}$

That said, we did not predict diversity shifts based on climate change projections, as our null (mean-field) models were consistently ranked as the best model. Projections from global climate models forecast an increase in temperatures for the region $\left(\sim 5^{\circ} \mathrm{C}\right)$ and a decrease in annual rainfall by as much as $25 \%{ }^{31}$ by 2070 . This implies a possible decrease in diversity, given the positive (albeit weak) correlation with annual rainfall.

This leads to a further interesting finding of our study: ie, the relatively high contribution of $\beta$-diversity (both $\beta_{\mathrm{S}}$ and $\beta_{\mathrm{R}}$ ) toward $\gamma$-diversity for the region (Figures 2 and 3 ), and thus the usefulness of the additive approach. This pattern appears to be typical of arid regions, both within Australia and globally. For example, a meta-analysis of (mammal) diversity across global desert regions found a marked pattern of both low $\alpha$ - and high $\beta$-diversity, ${ }^{44}$ and Bowman ${ }^{14}$ found the same disparity for Australian woody plant species (using the multiplicative approach). Similar findings have also been shown for dissimilar biomes - among Caribbean reef fishes, ${ }^{23}$ temperate plants from northern Germany, ${ }^{19,20}$ and subtropical Chinese bird communities. ${ }^{22}$

High $\beta$-diversity within arid Australia could be attributed to micro-habitat variation (as determined by elevation). Other factors could include spatial heterogeneity in soil type, although our data indicate otherwise ( $4 \%$ of DE, Table 2$)$, or human activity.

Recent human impacts in arid Australia, notably pastoral activity, introduced species, and shifts in fire regimes, may have contributed toward habitat patchiness and thus high $\beta$-diversity. Pastoral activity can, through disturbance, lead to enhanced $\beta_{\mathrm{s}}$-diversity. ${ }^{45}$ Conversely, some studies have specifically tested the impacts of grazing on $\beta$-diversity in arid regions (including Australia) and have found no or little effect. ${ }^{10,46}$ Although pastoral activity did occur on some properties in the southern parts of the AWNRM region, cattle 
Table 2 Outcome of generalized linear models $(\gamma$-distribution with log link) and information-theoretic model inference metrics, where species diversity is the response, and possible predictor variables are mean annual rainfall, mean annual temperature (averaged across vegetation groups), mean elevation, and dominant soil types (within each vegetation group)

\begin{tabular}{|c|c|c|c|c|c|}
\hline & k & $\mathbf{A I C}_{c}$ & $\Delta \mathbf{A I C}_{c}$ & $w_{i}$ & $\% \mathrm{DE}$ \\
\hline \multicolumn{6}{|c|}{ (A) $\alpha$-diversity as response and competing predictive variables } \\
\hline Null & 1 & 55.14 & 0.00 & 0.405 & 0.0 \\
\hline Mean annual rainfall & 2 & 56.75 & 1.61 & 0.181 & 12.0 \\
\hline Elevation & 2 & 57.53 & 2.39 & 0.123 & 5.8 \\
\hline Mean annual temperature & 2 & 58.13 & 3.00 & 0.091 & 0.5 \\
\hline Soil type & 2 & 58.19 & 3.06 & 0.088 & 0.0 \\
\hline Mean rainfall and soil & 3 & 59.16 & 4.02 & 0.054 & 23.0 \\
\hline Mean rainfall and elevation & 3 & 60.43 & 5.30 & 0.029 & 14.0 \\
\hline $\begin{array}{l}\text { Mean temperature } \\
\text { and elevation }\end{array}$ & 3 & 61.46 & 6.32 & 0.017 & 5.8 \\
\hline Mean temperature and soil & 3 & 62.04 & 6.90 & 0.013 & 0.7 \\
\hline \multicolumn{6}{|c|}{ (B) $\beta_{\mathrm{s}}$-diversity as response and competing predictive variables } \\
\hline Null & 1 & 161.43 & 0.00 & 0.359 & 0.0 \\
\hline Mean annual rainfall & 2 & 162.49 & 1.06 & 0.211 & 15.0 \\
\hline Elevation & 2 & 163.36 & 1.93 & 0.137 & 9.1 \\
\hline Soil type & 2 & 163.95 & 2.52 & 0.102 & 4.4 \\
\hline Mean annual temperature & 2 & 164.17 & 2.74 & 0.091 & 2.6 \\
\hline Mean rainfall and elevation & 3 & 166.15 & 4.71 & 0.034 & 17.0 \\
\hline Mean rainfall and soil & 3 & 166.31 & 4.88 & 0.031 & 16.0 \\
\hline $\begin{array}{l}\text { Mean temperature } \\
\text { and elevation }\end{array}$ & 3 & 167.24 & 5.81 & 0.020 & 9.4 \\
\hline Mean temperature and soil & 3 & 167.82 & 6.39 & 0.015 & 4.9 \\
\hline \multicolumn{6}{|c|}{ (C) $\gamma$-diversity as response and competing predictive variables } \\
\hline Null & 1 & 161.45 & 0.00 & 0.355 & 0.0 \\
\hline Mean annual rainfall & 2 & 162.45 & 1.00 & 0.215 & 16.0 \\
\hline Elevation & 2 & 163.34 & 1.90 & 0.137 & 9.3 \\
\hline Soil type & 2 & 163.96 & 2.51 & 0.101 & 4.5 \\
\hline Mean annual temperature & 2 & 164.18 & 2.73 & 0.090 & 2.7 \\
\hline Mean rainfall and elevation & 3 & 166.09 & 4.64 & 0.035 & 18.0 \\
\hline Mean rainfall and soil & 3 & 166.26 & 4.81 & 0.032 & 17.0 \\
\hline $\begin{array}{l}\text { Mean temperature } \\
\text { and elevation }\end{array}$ & 3 & 167.22 & 5.77 & 0.020 & 9.7 \\
\hline Mean temperature and soil & 3 & 167.83 & 6.38 & 0.015 & 5.0 \\
\hline
\end{tabular}

Notes: Data are for (A) $\alpha$-diversity, (B) $\beta_{\mathrm{s}}$-diversity, and (C) $\gamma$-diversity. Shown are the number of fitted model parameters ( $k$; includes intercept), Akaike's corrected information criterion (AIC), difference from best model $\left(\triangle A I C_{c}\right)$, Akaike weight scaled relative to a total sum of $I\left(w_{i}\right)$, and percentage deviance explained $(\% D E)$. \%DE is a measure of the structural goodness of fit of the model.

are now mostly restricted to parts of the north of the AWNRM region, particularly the Anangu Pitjantjatjara Yankunytjatjara lands (see http://www.awnrm.sa.gov.au). We did not have the cattle abundance data required to test for a density effect on species diversity.

Recent experimental plot-based studies suggest that fire has no substantial effect on $\beta$-diversity, particularly where underlying drivers (of diversity) such as gradient remained unchanged. ${ }^{47}$ Conversely, other research has shown that fire can drive plant species turnover, but typically where the species are either fire tolerant or fire dependent. ${ }^{48}$ We lack information on fire history for the study region, but speculate that the relatively low fuel loads in arid regions do not support frequent hot fires.

Although our findings provide insight into the relative contributions made by diversity indices to communities, the correlative models failed to provide adequate explanation of the underlying mechanisms of diversity distribution in arid SA. We concede that the spatial scale of available data (broad and nonrandom, thus requiring determination of diversity across MVGs) may have contributed toward a lack of evidence for our models (power to resolve effects is low because we could fit only eleven data points, see Burnham and Anderson ${ }^{35}$ ), and thus advocate the site-specific collation of parameters likely to determine diversity, including local rainfall and temperature patterns, fire history, aspect, and cattle densities. Indeed, the biological surveys run through the relevant Government authorities require reconsideration, and new transects should be developed using a stratified random approach. Systematic collation of data, along south-north transects, for example, will provide the data needed to better address concerns regarding outcomes under global change.

\section{Acknowledgments}

We thank S Delean for advice on data analysis. Funding was provided by the Alinytjara Wilurara Natural Resource Management Board, South Australia, and the Australian Research Council Linkage Project LP0989420.

\section{Disclosure}

The authors report no conflicts of interest in this work.

\section{References}

1. Myers N, Mittermeier RA, Mittermeier CG, da Fonseca GAB, Kent J. Biodiversity hotspots for conservation priorities. Nature. 2000;403(6772): 853-858.

2. Walker B, Salt D. Resilience thinking. London, UK: Island Press; 2006.

3. Loreau M, Naeem S, Inchausti P, et al. Biodiversity and ecosystem functioning: current knowledge and future challenges. Science. 2001;294(5543):804-808.

4. Hodgson JA, Thomas CD, Wintle BA, Moilanen A. Climate change, connectivity and conservation decision making: back to basics. $J$ Appl Ecol. 2009;46(5):964-969.

5. Samir KC, Barakat B, Goujon A, Skirbekk V, Sanderson W, Lutz W. Projection of populations by level of educational attainment, age, and sex for 120 countries for 2005-2050. Demogr Res. 2010;22: 383-472.

6. Brook BW, Sodhi NS, Bradshaw CJA. Synergies among extinction drivers under global change. Trends Ecol Evol. 2008;23(8):453-460.

7. Chapin FS, Zavaleta ES, Eviner VT, et al. Consequences of changing biodiversity. Nature. 2000;405(6783):234-242. 
8. Colwell RK, Coddington JA. Estimating terrestrial biodiversity through extrapolation. Philos Trans R Soc Lond B Biol Sci. 1994;345(1311): 101-118.

9. James $\mathrm{CD}$, Shine R. Why are there so many coexisting species of lizards in Australian deserts? Oecologia. 2000;125(1):127-141.

10. Fensham RJ, Fairfax RJ, Dwyer JM. Vegetation responses to the first 20 years of cattle grazing in an Australian desert. Ecology. 2010;91(3): 681-692.

11. Cowling RM, Rundel PW, Lamont BB, Arroyo MK, Arianoutsou M. Plant diversity in Mediterranean-climate regions. Trends Ecol Evol. 1996;11(9):362-366.

12. Liberal CN, Isidro de Farias AM, Meiado MV, Filgueiras BKC, Iannuzzi L. How habitat change and rainfall affect dung beetle diversity in Caatinga, a Brazilian semi-arid ecosystem. J Insect Sci. 2011;11:1-11.

13. Magurran AE. Measuring biological diversity. Oxford, UK: Blackwell Science; 2004.

14. Bowman D. Diversity patterns of woody species on a latitudinal transect from the monsoon tropics to desert in the Northern Territory, Australia. Aust J Bot. 1996;44(5):571-580.

15. Westoby M. Two main relationships among the components of species richness. Proceedings of the Ecological Society of Australia. 1985;14: 103-107.

16. Whittaker RH. Vegetation of the Siskiyou Mountains, Oregon and California. Ecol Monogr. 1960;30(3):280-338.

17. Gering JC, Crist TO, Veech JA. Additive partitioning of species diversity across multiple spatial scales: Implications for regional conservation of biodiversity. Conserv Biol. 2003;17(2):488-499.

18. Veech JA, Summerville KS, Crist TO, Gering JC. The additive partitioning of species diversity: recent revival of an old idea. Oikos. 2002;99(1): 3-9.

19. Clough Y, Holzschuh A, Gabriel D, et al. Alpha and beta diversity of arthropods and plants in organically and conventionally managed wheat fields. J Appl Ecol. 2007;44(4):804-812.

20. Klimek S, Marini L, Hofmann M, Isselstein J. Additive partitioning of plant diversity with respect to grassland management regime, fertilisation and abiotic factors. Basic Appl Ecol. 2008;9(6):626-634.

21. Sodhi NS, Koh LP, Clements R, et al. Conserving Southeast Asian forest biodiversity in human-modified landscapes. Biol Conserv. 2010;143(10):2375-2384.

22. Wu F, Yang XJ, Yang JX. Additive diversity partitioning as a guide to regional montane reserve design in Asia: an example from Yunnan Province, China. Divers Distrib. 2010;16(6):1022-1033.

23. Rodriguez-Zaragoza FA, Arias-Gonzalez JE. Additive diversity partitioning of reef fishes across multiple spatial scales. Caribb J Sci. 2008;44(1):90-101.

24. Burbidge AA, McKenzie NL, Brennan KEC, et al. Conservation status and biogeography of Australia's terrestrial mammals. Aust J Zool. 2008;56(6):411-422.

25. Letnic M, Koch F, Gordon C, Crowther MS, Dickman CR. Keystone effects of an alien top-predator stem extinctions of native mammals. Proc Biol Sci. 2009;276(1671):3249-3256.

26. Reynolds JF, Stafford Smith DM, Lambin EF, et al. Global desertification: building a science for dryland development. Science. 2007;316(5826):847-851.

27. Sommer JH, Kreft H, Kier G, Jetz W, Mutke J, Barthlott W. Projected impacts of climate change on regional capacities for global plant species richness. Proc Biol Sci. 2010;277(1692):2271-2280.

Research and Reports in Biodiversity Studies

\section{Publish your work in this journal}

Research and Reports in Biodiversity Studies is an international, peerreviewed, open access journal publishing original research, reports, reviews and commentaries on all areas of biodiversity research. The manuscript management system is completely online and includes a
28. Hijmans RJ, Cameron SE, Parra JL, Jones PG, Jarvis A. Very high resolution interpolated climate surfaces for global land areas. International Journal of Climatology. 2005;25(15):1965-1978.

29. DEWR. Australia's native vegetation: a summary of Australia's major vegetation groups. Canberra, Australia: Department of the Environment and Water Resources; 2007.

30. Koenig WD. Spatial autocorrelation of ecological phenomena. Trends Ecol Evol. 1999;14(1):22-26.

31. Suppiah R, Preston B, Whetton PH, et al. Climate change under enhanced greenhouse conditions in South Australia. Australia: CSIRO; 2006.

32. West P. Assessing invasive animals in Australia. Canberra, Australia: NLWRA; 2008.

33. Stohlgren TJ, Guenther DA, Evangelista PH, Alley N. Patterns of plant species richness, rarity, endemism, and uniqueness in an arid landscape. Ecol Appl. 2005;15(2):715-725.

34. Northcote KH. A Factual Key for the Recognition of Australian Soils. 4th ed. Glenside, South Australia: Rellim Technical; 1979.

35. Burnham KP, Anderson DR. Kullback-Leibler information as a basis for strong inference in ecological studies. Wildlife Research. 2001;28(2): 111-119.

36. Fawcett RJB, Jones DA, Shitaye B. Climatological rainfall analyses for Southeast South Australia. Adelaide, Australia: National Climate Centre; 2006.

37. Waide RB, Willig MR, Steiner CF, et al. The relationship between productivity and species richness. Аnпи Rev Ecol Syst. 1999;30:257-300.

38. Gaston KJ. Global patterns in biodiversity. Nature. 2000;405(6783): 220-227.

39. Slatyer C, Rosauer D, Lemckert F. An assessment of endemism and species richness patterns in the Australian Anura. J Biogeogr. 2007;34(4): 583-596.

40. Barrett G, Silcocks A, Barry S, Cunningham R, Poulter R. The new atlas of Australian birds. Melbourne, Australia: Birds Australia; 2003.

41. Byrne M, Yeates DK, Joseph L, et al. Birth of a biome: insights into the assembly and maintenance of the Australian arid zone biota. Mol Ecol. 2008;17(20):4398-4417.

42. Simmons MT, Cowling RM. Why is the Cape Peninsula so rich in plant species? An analysis of the independent diversity components. Biodivers Conserv. 1996;5(5):551-573.

43. Scherrer D, Korner C. Topographically controlled thermal-habitat differentiation buffers alpine plant diversity against climate warming. J Biogeogr. 2011;38(2):406-416.

44. Kelt DA, Brown JH, Heske EJ, et al. Community structure of desert small mammals: Comparisons across four continents. Ecology. 1996;77(3):746-761.

45. Schneider NA, Griesser M. Influence and value of different water regimes on avian species richness in arid inland Australia. Biodivers Conserv. 2009;18(2):457-471.

46. Zhang W. Changes in species diversity and canopy cover in steppe vegetation in Inner Mongolia under protection from grazing. Biodivers Conserv. 1998;7(10):1365-1381.

47. Reilly MJ, Wimberly MC, Newell CL. Wildfire effects on beta-diversity and species turnover in a forested landscape. J Veg Sci. 2006;17(4): 447-454.

48. Uys RG, Bond WJ, Everson TM. The effect of different fire regimes on plant diversity in southern African grasslands. Biol Conserv. 2004;118(4):489-499.

\section{Dovepress}

very quick and fair peer-review system. Visit http://www.dovepress.com/ testimonials.php to read real quotes from published authors. 